Running head: INHIBTION AND FACILITATION IN PREVIEW SEARCH

\title{
Visuospatial working memory mediates inhibitory and facilitatory guidance in preview search
}

Doug J. K Barrett ${ }^{1}$, Steven S. Shimozaki ${ }^{1}$, Silke Jensen ${ }^{1}$ \& Oliver Zobay ${ }^{2}$

${ }^{1}$ University of Leicester, United Kingdom

2MRC Institute of Hearing Research, Nottingham, United Kingdom

Author Note

Correspondence regarding this article should be addressed to Doug J. K. Barrett, Department of Neuroscience, Psychology and Behaviour, University of Leicester, Leicester, LE1 9HN. Tel: +44(0)116 229 7178; Email: djkb1@leicester.ac.uk 


\section{Visuospatial working memory mediates inhibitory and facilitatory guidance in preview search}

Abstract

Visual search is faster and more accurate when a subset of distractors is presented before the display containing the target. This "preview benefit" has been attributed to separate inhibitory and facilitatory guidance mechanisms during search. In the preview task the temporal cues thought to elicit inhibition and facilitation provide complementary sources of information about the likely location of the target. In this study, we use a Bayesian Observer model to compare sensitivity when the temporal cues eliciting inhibition and facilitation produce complementary, and competing, sources of information. Observers searched for $T$-shaped targets among $L$-shaped distractors in two standard and two preview conditions. In the standard conditions, all the objects in the display appeared at the same time. In the preview conditions, the initial subset of distractors either stayed on the screen or disappeared before the onset of the search display, which contained the target when present. In the latter, the synchronous onset of old and new objects negates the predictive utility of stimulus-driven capture during search. The results indicate observers combine memory-driven inhibition and sensory-driven capture to reduce spatial uncertainty about the target's likely location during search. In the absence of spatially predictive onsets, memorydriven inhibition at old locations persists despite irrelevant sensory change at previewed locations. This result is consistent with a bias towards unattended objects during search via the active suppression of irrelevant capture at previously attended locations.

Keywords: Visual search, inhibition, facilitation, integration. 


\section{Introduction}

The ability to select relevant over irrelevant information is crucial for goaldirected behaviour. In visual search, this ability is assessed by measuring changes in the speed or accuracy of target detection in the presence of varying numbers of non-targets (distractors). Previous research has shown detection is enhanced when a subset of the distractors is presented prior to the onset of the search display. This enhancement, known as the preview benefit (Watson \& Humphreys, 1997), is thought to reflect observers' ability to use temporal information to exclude irrelevant distractors during search. This may be achieved by inhibiting activation at "old" locations in the preview, (Watson \& Humphreys, 1997), prioritising "new" objects as they appear in the search display (Donk \& Theeuwes, 2001; 2003), or a combination of both mechanisms (Olivers, Humphreys \& Braithwaite, 2006; von Mühlenen, Watson \& Gunnell, 2013). Support for the role of inhibition comes from studies that have used the dot-probe procedure to contrast the accuracy of detection at old and new locations: Probes at old locations are typically harder to detect than those at new locations (Humphreys, Stalmann, \& Olivers, 2004). This inhibition only occurs when probe-detection is embedded within a search task, suggesting observers use the preview to attenuate visual input at old locations (Humphreys et al., 2004; Kunar, Humphreys, Smith, \& Hulleman, 2003; Watson, Humphreys, \& Olivers, 2003). Inhibition has also been shown to generalise from previewed locations to previewed features such as colour and shape (Braithwaite \& Humphreys, 2007; Watson et al., 2003). Inhibitory guidance has also been shown to persist in dynamic displays, suggesting the preview benefit is mediated by the active suppression of features when the location of previewed objects change (Andrews, Watson, Humphreys \& Braithwaite, 2011; Watson, Humphreys \& Olivers, 2003; Humphreys, Olivers, \& Braithwaite, 2006).

The findings above suggest observers maximise efficiency by excluding the locations or features of old objects during search. Findings from other studies, however, have emphasised the contribution of facilitation to the preview benefit. This is usually attributed to the reflexive prioritisation of new items as they appear in the display (Donk, Agter, \& Pratt, 2009; Donk \& Theeuwes, 2001; 2003). 
Luminance onsets are known to elicit attentional capture, and the generation of the preview benefit is reduced or slowed when new items are equiluminant with the background of the display (Braithwaite, Hulleman, Watson, \& Humphreys, 2006). Electrophysiological data indicate attentional capture modulates target processing within approximately 200-ms of the onset of the search display, while inhibition is associated with a sustained negativity between 350 and 750 -ms after the onset of the preview display (Jacobsen, Humphreys, Schröger, \& Roeber, 2002; Kiss \& Eimer, 2011). These findings suggest attentional capture and inhibition elicit complementary sources of information about the likely location of the target before and during search. When luminance changes at old locations coincide with the onset of the search display, however, the predictive utility of attentional capture is compromised, because it occurs at old and new locations. This happens when the preview is extinguished prior to its reappearance with the search display, or when old items flash on and off as the search display appears (Watson \& Humphreys, 1997; Kunar, Humphreys \& Smith, 2003). In these situations, the preview benefit is reduced or abolished. Watson and Humphreys (1997; 2002) interpreted these findings as evidence of an adaptive mechanism that overrides inhibition when sensory change occurs at old locations. This possibility would distinguish inhibition in the preview task from the visual working memory (VWM) resources thought to mediate temporal coherence as movements of the observer or objects in the scene produce changes in the retinal image associated with sensory inputs (Al-Aidroos, Emrich, Ferber, \& Pratt, 2012; Hollingworth, Richard, \& Luck, 2008; Jiang \& Wang, 2004; Phillips, 1974; Pylyshyn \& Storm, 1988).

An alternative explanation is that competition between inhibition and attentional capture simply reduces the signal-to-noise ratio during search when old and new items appear together (Allen \& Humphreys, 2007). In this situation, accurate performance requires observers to maintain a representation of the preview in the face of irrelevant luminance onsets or changes at old locations. The extent that observers can intentionally suppress attentional capture remains controversial (Belopolsky, Schreij, \& Theeuwes, 2010), however; any reduction of inhibition would reduce the preview benefit by increasing the number of potential target locations during search. Increasing spatial uncertainty about the target's location is also likely to elicit a concomitant shift in observers' response 
thresholds, with the increased likelihood of mistaking a distractor for the target eliciting slower, more conservative responses (Palmer, Verghese, \& Pavel, 2000; Palmer, 1998; Smith, 2010). The use of RTs to measure the preview benefit in the majority of studies renders the distinction between changes in sensitivity and response criterion opaque. Differentiating the way temporal cues impact upon observers' ability to use VWM to exclude irrelevant distractors, however, is likely to provide important information about the way inhibition and attentional capture interact to guide selection during search.

The current study investigates whether onset transients or sensory change necessarily abolishes memory-driven inhibition in preview search. To do this, we employed a Bayesian Observer analysis (BO) to contrast discriminability (sensitivity) and response criteria during standard and preview searches. BO analysis is a subset of signal detection theory (SDT) that has been used to model search when the target location is predictively cued (Eckstein, 2011; Palmer, 1994; Shimozaki, 2010; Shimozaki, Schoonveld, \& Eckstein, 2012; Verghese, 2001) Unlike RT analyses, SDT/BO models provide a statistical framework for differentiating changes in observers' sensitivity and response criterion. According to SDT/BO models of search, target and distractor stimuli are represented as continuous random distributions. The variance of these distributions is typically assumed to be equal, and target discriminability is determined by the normalised difference between them $\left(d^{\prime}\right)$. In a "yes-no" task, locations in the display are sampled in parallel for evidence of the target. The observer calculates the posterior probabilities for target presence and absence and compares the ratio of these to a decision criterion $(\lambda)$. If the ratio exceeds $\lambda$, the observer responds target-present. If not, the observer responds target-absent. As the conditional probability of the target's presence is computed across all items in the display, the SDT/BO model can be used to compare sensitivity when the temporal cues distinguishing old from new items provide complementary or competing information about the subset of locations likely to contain a target.

To manipulate the predictive utility of temporal cues during search we used four conditions. Standard search conditions presented a single display in which the target could be present or absent: Full-standard displays were used to estimate $d^{\prime}$ and $\lambda$ values for each observer at set sizes of 4 and 8; Half-standard displays 
were used to estimate $d^{\prime}$ and $\lambda$ when each set size was halved. Performance in these conditions was compared against two preview conditions. In the No-gap condition, the search display was preceded by a preview display that remained on the screen until the search array appeared. In this condition, inhibition and attentional capture provide complementary information about the subset of locations in which the target can appear. In the Gap condition, the preview display was extinguished one second before reappearing at the same time as the search display. In this condition, the preview specifies locations that are irrelevant for the forthcoming search, while attentional capture driven by the onsets in the search display is non-predictive of target location. If inhibition at old locations is 'reset' by sensory change, the synchronous onset of old and new items in the Gap condition should abolish the preview benefit. If, however, observers are able to suppress attentional capture at old locations, the synchronous onset of the preview and search displays should expose the contribution of inhibition. Furthermore, this contribution is likely to be emphasised when the number of new locations equals the capacity of the mechanisms thought to mediate attentional capture (Yantis \& Jones, 1991). To assess this possibility, we contrasted estimates of $d^{\prime}$ and $\lambda$ in standard and preview search conditions at different set sizes.

\section{Method: Experiment 1}

\subsubsection{Observers}

54 observers were recruited to the study. 24 were male and age ranged from 18 to 48 years $\left(M_{\text {age }}=21.2, S D=5.69\right)$. All reported normal or normal-to-corrected vision and were naïve to the purpose of the study.

\subsubsection{Apparatus}

The experiment was run on an IBM PC with a 19' CRT View Sonic G90fB monitor (Walnut, CA, USA). The display resolution was $1240 \times 768$ pixels and the frame rate was $85 \mathrm{~Hz}$. Stimulus presentation and data collection were controlled using custom-built software in MATLAB (Mathworks, Natick, MA, USA) with Psychophysics toolbox extensions (Brainard, 1997; Kleiner et al., 2007). Viewing distance was maintained at $57 \mathrm{~cm}$ using a fixed chin rest and responses were 
INHIBITION AND FACILITATION IN PREVIEW SEARCH

collected using a Cedrus RB-350 Response Pad (San Pedro, CA, USA). The experiment was conducted in a quiet, dimly lit room.

\subsubsection{Stimuli}

Observers searched for a T-shaped target among L-shaped distractors. The intersection of the bars on the target occurred at the mid-point of the short bar. On distractors, the intersection of the long and short bars produced a right angle. Distractors were rotated $180^{\circ}$ relative to the target and the target and distractors could be presented at $90^{\circ}$ or $270^{\circ}$ of rotation from the vertical (see Figure 1). Stimuli subtended $1.6^{\circ} \times 1^{\circ}$ on the circumference of a virtual circle with a radius of $8^{\circ}$ and 12 equally spaced locations corresponding to the digits on a clock face. Stimuli were mid-grey $\left(24 \mathrm{~cd} / \mathrm{m}^{2}\right)$ and presented on a uniform black $\left(0.33 \mathrm{~cd} / \mathrm{m}^{2}\right)$ background (see Figure 1). 


\subsubsection{Procedure}

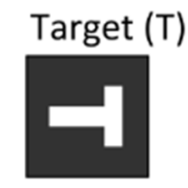

Distractors (D)

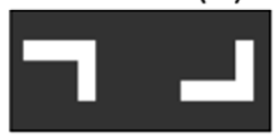

Preview No-gap

Preview Gap

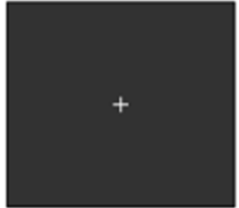

$1000 \mathrm{~ms}$
Standard-full

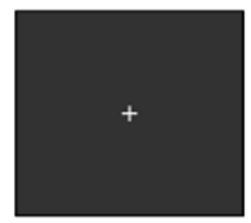

$1000 \mathrm{~ms}$

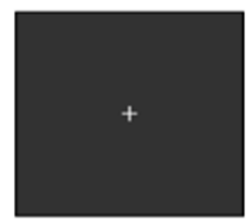

$1000 \mathrm{~ms}$

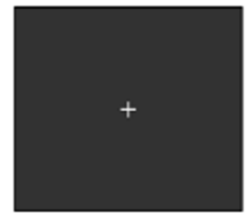

$1000 \mathrm{~ms}$

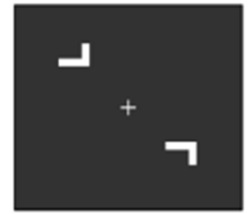

$2000 \mathrm{~ms}$

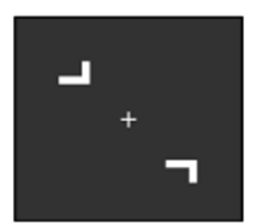

$2000 \mathrm{~ms}$

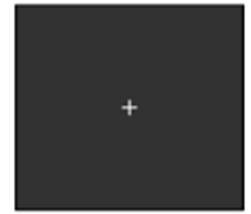

$1000 \mathrm{~ms}$

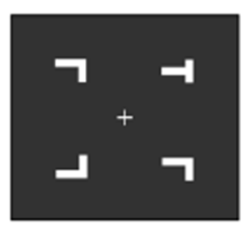

$24 \mathrm{~ms}$

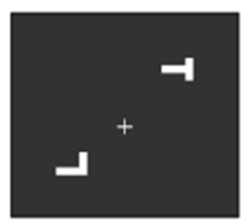

$24 \mathrm{~ms}$

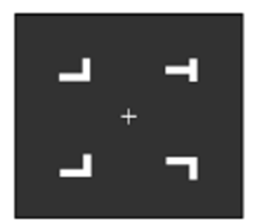

$24 \mathrm{~ms}$

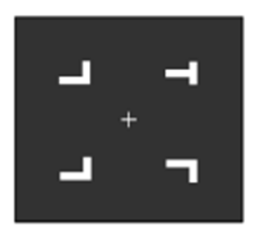

$24 \mathrm{~ms}$

Figure 1. Sequence of events for each search conditon on a target-present trial at set size 4. Standard-full and Standard-half displays provide baseline estimates for detection performance in the No-gap and Gap conditons. Stimuli are not draw to scale and were presented at one of 12 locations arranged in a virtual circle around the fixation in actual displays.

Figure 1 illustrates the sequence of events on each trial in the standard (Full and Half display) and preview search conditions (Gap and No-gap). Trials began with a fixation cross at the centre of the screen and ended with a search display. Search displays were presented for 24 -ms and contained a target on $50 \%$ of trials. In the standard conditions, search displays followed an initial fixation of 1000-ms. In the No-gap condition, search displays were preceded by a preview display, which remained on the screen when the search array appeared 2000-ms later. In the Gap condition, the preview and search displays were separated by an interstimulus-interval (ISI) of 2000-ms, during which a fixation cross was centred on an otherwise blank display. Following the ISI, the preview and search displays appeared at the same time. Preview displays had half the number of objects as search displays and contained distractors only. For example, at set size 4, preview displays contained 2 objects and search displays contained 4 objects; 2 old and 2 new. On target-absent trials, preview and search displays contained an equal 
number of both distractors. On target-present trials, the target replaced one distractor, which was randomly picked on each trial. Search displays could contain 2,4 or 8 objects randomly assigned to one of 12 locations and observers reported the presence or absence of the target using a button-press to signal "yes" or "no". Standard and preview trials were randomly interleaved in blocks of 160 trials, and observers completed 5 blocks to generate 100 responses in each search type by set size condition.

\subsubsection{Bayesian model for preview search}

The observer's task is to detect a target (T) among distractors, or 'noise' stimuli, $(N)$ in one of $M$ possible locations. Following SDT convention, we assume target and distractors elicit Gaussian responses of equal variance (Green, \& Swets, 1966; Wickens, 2001). In this case, we set the mean target response to zero and the mean response to each distractor as $\pm d^{\prime}$. The Bayesian Observer computes the posterior probabilities of target presence and absence, given the responses $\mathbf{x}=\left(x_{1}\right.$, $\left.X_{2}, \ldots, X_{M}\right)$ at all locations $1, \ldots, \mathrm{M}$, or $p(T \mid \mathbf{x})$ and $p(N \mid \mathbf{x})$, respectively. These can be calculated by adding the posterior probabilities of $\mathbf{x}$ for all possible arrangements of objects in target-present and target-absent displays, respectively. By Bayes' theorem these can be calculated with the prior probabilities of target presence/absence $(p(T), p(N))$, and the prior probabilities of the responses $(\mathbf{x})$, given target presence/absence $(p(\mathbf{x} \mid T)$ and $p(\mathbf{x} \mid N)$, or the likelihoods). Assuming independence, and substituting the Gaussian assumption, the likelihood of target presence at location $i$ on a single trial is given by:

$$
l_{i, T_{i}}=p\left(x_{i} \mid T_{i}\right) \prod_{j=1, j \neq i}^{M} p\left(x_{j} \mid N_{j}\right)=\phi\left(x_{i}\right) \prod_{j=1, j \neq i}^{M} \phi\left(x_{j}-d^{\prime}\right),
$$

with $\Phi$ equal to the Gaussian probability density function. For simplicity, the equation above presents the general expression when all distractors in the display are the same (see the appendix for a complete derivation of the model for displays containing distractors at $\pm d$ ' at all possible spatial arrangements). Also, note that zero is the mean for the target distribution and $d^{\prime}$ is the mean for the distractor distribution for this model. In a yes-no task, the Bayesian Observer generates a 
response by calculating the posterior probability of target presence over that of target absence, given the vector of responses at each location (x). Using Bayes' theorem, assuming equal numbers of target present and target absent trials, and with equal probability of the target appearing at any location,

$$
\frac{p(T \mid \mathbf{x})}{p(N \mid \mathbf{x})}=\frac{p(\mathbf{x} \mid T)}{p(\mathbf{x} \mid N)}=\frac{l_{T}}{l_{N}}=\frac{\sum_{i=1}^{M} l_{i, T_{i}} / M}{\prod_{i=1}^{M} \phi\left(x_{i}-d^{\prime}\right)}
$$

Where $l_{T}$ is the likelihood of target presence (over all locations i), and $l_{N}$ is the likelihood of target absence. The logarithm of this value is then compared to a decision criterion $(\lambda)$. If the logarithm of the likelihood ratio is equal or exceeds $\lambda$, the observer responds "yes". If the log likelihood ratio is less than $\lambda$, the observer responds "no".

To fit the Bayesian model to human data, $d^{\prime}$ and $\lambda$ were systematically varied to estimate the hit and false alarm rates that best fit each observer's performance. Parameter estimates for all potential target and distractor arrangements were generated using Monte Carlo simulations, with 50,000 repetitions for each search type by set size condition (Kupinski, Hoppin, Clarkson, \& Barrett, 2003; Shimozaki, Eckstein, \& Abbey, 2003; Shimozaki et al., 2012). Importantly, the SDT/BO model provides estimates of $d^{\prime}$ that are independent of the increase in decision noise associated with larger set sizes, as well as changes in the observer's decision criteria as the task gets harder.

In the current study, the standard search conditions represent baseline measures for performance in the preview conditions. Half displays provide an estimate of optimal use of the preview to exclude irrelevant locations during search. Full displays provide an estimate of performance when observers are unable to exclude the preview locations during search. To contrast performance in the standard search baselines with that in the preview conditions, performance in the Gap and No-gap displays were fit for half and full display models. These estimated the best fitting $d^{\prime}$ and $\lambda$ values for searches that are i) restricted to objects in the search display or ii) include objects in the search and preview displays. Subtracting the estimates in standard-half displays from those in preview-half displays provides an index of the reduction in performance in 
preview compared to standard-half search displays. Subtracting estimates in standard-full from those in preview-full displays provides an estimate of the benefit in preview compared to standard-full search displays.

For human observers, point estimates of $d^{\prime}$ and $\lambda$ were obtained by minimising $\chi^{2}$. For a given set of $d^{\prime}$ and $\lambda$ values $\chi^{2}$ was determined using the standard expression $\chi^{2}=\sum\left(E_{i}-O_{i}\right)^{2} / E_{i}$, where $E_{i}$ and $O_{i}$ are the estimated and observed response frequencies respectively for hits and false alarms. As the number of input parameters (hit and false alarm rate) was equal to the number of free parameters ( $d^{\prime}$ and $\lambda$ ), the models were exactly identified, and $\chi^{2}$ was expected to be near 0 for the estimated parameters. This is similar to the conversion of hits and false alarm rates to d's and in SDT calculations in standard yes-no tasks (e.g., Green \& Swets, 1974: See supplementary information for a full derivation of the model estimation and fitting procedures).

\section{Results: Experiment 1}

\subsubsection{Accuracy Data}

Standard-full displays at set size 4 and Standard-half displays at set size 8 are equivalent, thus data in these conditions were averaged. A $3 \times 2$ repeated measures ANOVA on proportion correct with search type (Standard-full, No-gap and Gap) and set size $(4,8)$ as within-subjects factors yielded significant main effects of search type $\left(F_{2,106}=86.749, p<0.001, \eta_{p}{ }^{2}=0.621\right)$ and set size $\left(F_{1,53}=\right.$ 431.131, $\left.p<0.001, \eta_{p}^{2}=0.891\right)$. Observers were more accurate on preview Nogap and Gap than on standard searches at set sizes of $4(+0.075,+0.011)$ and $8(+$ $0.095,+0.052)$ respectively. The Search type $x$ Set size interaction term was also significant $\left(F_{2,106}=5.151, p=0.007, \eta_{p}^{2}=0.089\right)$, reflecting a smaller decrease in accuracy in the No-gap compared to the Gap condition at set size 8 (.042) than 4 (.064). Post hoc tests revealed a significant increase in accuracy in all preview compared to the standard-full conditions except the Gap condition at set size 4 ( $p$ s $<0.05$ ). The accuracy data, therefore, provide evidence for improved accuracy in both the Gap and No-gap compared to the Standard-full displays and better performance in the No-gap compared to the Gap condition at set sizes 4 and 8. 
Table 1. Mean proportion of hits $[p(\mathrm{H})]$, false alarms $[p(\mathrm{~F})]$ and correct responses $[p[\mathrm{C})]$ by set size and search condition in Experiment 1 . S-half and S-full denote standard-full displays respectively.

\begin{tabular}{lcccccc}
\hline & \multicolumn{3}{c}{ Set Size 4} & \multicolumn{3}{c}{ Set Size 8 } \\
\cline { 2 - 7 } Condition & $p(\mathrm{H})$ & $p(\mathrm{~F})$ & $P(\mathrm{C})$ & $p(\mathrm{H})$ & $p(\mathrm{~F})$ & $p(\mathrm{C})$ \\
\hline S-half & 0.89 & 0.13 & 0.88 & 0.82 & 0.21 & 0.81 \\
No-Gap & 0.88 & 0.12 & 0.88 & 0.75 & 0.21 & 0.77 \\
Gap & 0.85 & 0.21 & 0.82 & 0.71 & 0.26 & 0.73 \\
S-full & 0.82 & 0.22 & 0.80 & 0.67 & 0.32 & 0.68 \\
\hline
\end{tabular}

\subsubsection{Model estimates and fits}

Table 2 presents the mean parameter estimates of the best fitting model for each observer in standard and preview searches at set sizes 4 and 8 . Estimates for each type of search reveal a general decrease in $d^{\prime}$ and an increase in $\lambda$ as the number of items in the display gets larger. In the SDT/BO model, the values of $d^{\prime}$ highlight the independent effects of resource allocation and increased decision noise on observers' accuracy as set size increases, as decision noise does not change $d^{\prime}$ with set size in this model (Eckstein, 2011; Mazyar, van den Berg, \& Ma, 2012; Shimozaki, 2010). Thus, the reduction in $d^{\prime}$ indicates an inverse relationship between sensitivity and set size that is consistent with resource- or capacitylimited search (Barrett \& Zobay, 2014; Cameron, Eckstein, Tai, \& Carrasco, 2004; McElree \& Carrasco, 1999). The increase in $\lambda$ also reveals a tendency towards target-absent responses as set size increases (with $\lambda=0$ indicating an unbiased observer). In the subsequent analyses, we focus on changes in observers' sensitivity $(d$ ') when inhibition and attentional capture provide complementary or conflicting information about the subset of items in which the target could appear.

To compare sensitivity in the preview with that in standard search conditions, we calculated separate cost and benefit indices in the No-gap and Gap conditions at set sizes 4 and 8 . Costs were calculated by subtracting individual $d^{\prime}$ estimates in Standard-half from those in the Preview-half models. Benefits were 
INHIBITION AND FACILITATION IN PREVIEW SEARCH

calculated by subtracting individual $d$ ' estimates in the Preview-full from those in the Standard-full model.

Table 2. Mean estimated model parameters and fits by set size and search condition in Experiment 1.

\begin{tabular}{llrcrrrc}
\hline & & \multicolumn{3}{c}{ Full Display } & \multicolumn{3}{c}{ Half Display } \\
\cline { 3 - 8 } Search & S Size & $d^{\prime}$ & $\log (\lambda)$ & $\chi^{2}$ & $d^{\prime}$ & $\log (\lambda)$ & $\chi^{2}$ \\
\hline Standard & 4 & 2.45 & -0.16 & 0.04 & 2.94 & -0.17 & 0.08 \\
& 8 & 1.84 & 0.11 & 0.02 & 2.48 & -0.20 & 0.02 \\
No-gap & 4 & 3.14 & -0.23 & 0.14 & 2.89 & -0.17 & 0.07 \\
& 8 & 2.49 & 0.08 & $<0.01$ & 2.21 & 0.13 & $<0.01$ \\
Gap & 4 & 2.59 & -0.31 & $<0.01$ & 2.29 & -0.25 & $<0.01$ \\
& 8 & 2.19 & 0.11 & $<0.01$ & 1.91 & 0.16 & $<0.01$ \\
\hline
\end{tabular}
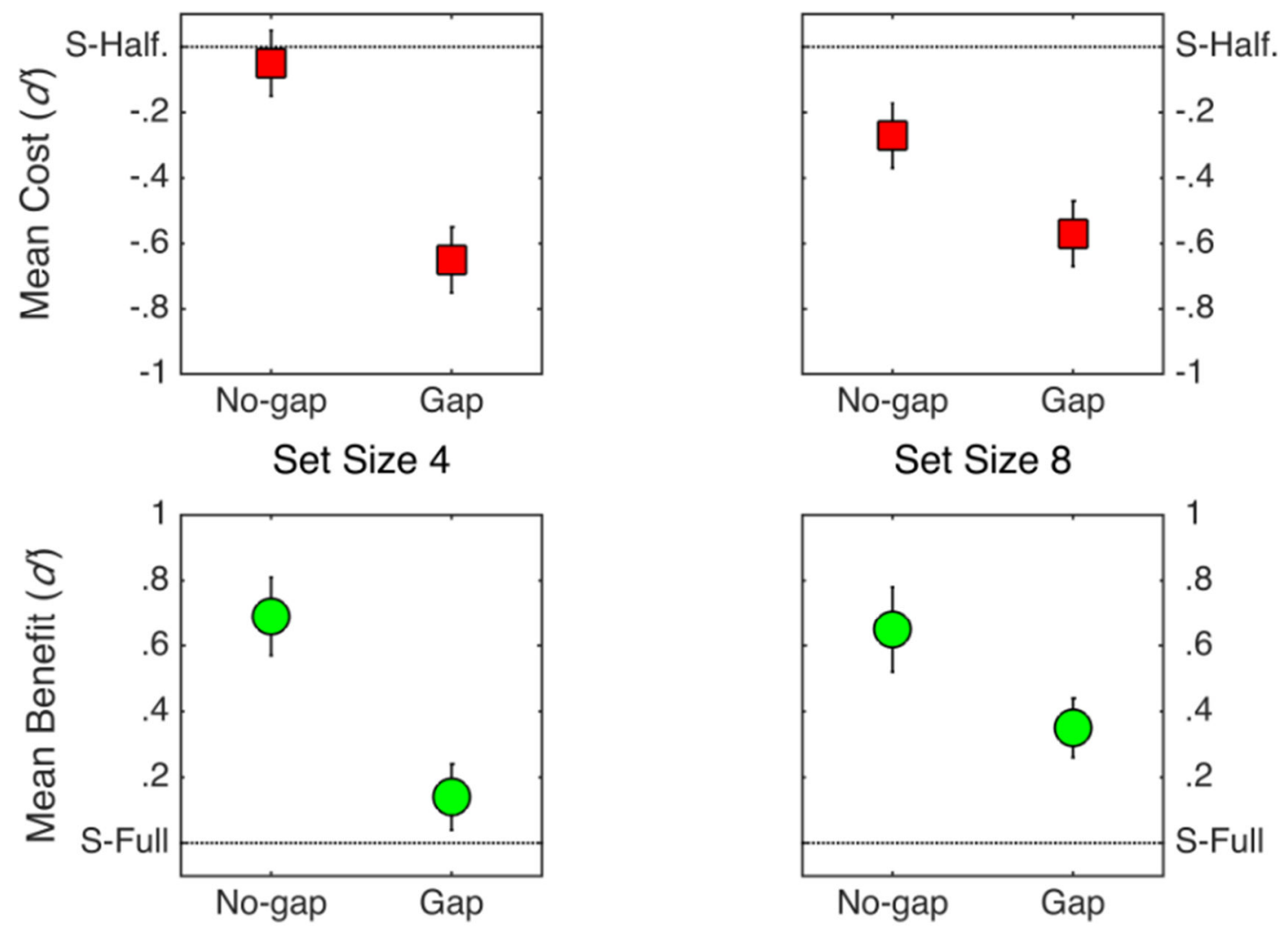

Figure 2. Mean cost and benefit estimates against Standard-half (panels A and B) and Standard-full (panels C and D) baselines in the No-gap and Gap conditions at set sizes 4 and 8. Error bars denote standard errors of the means. 
Panels A and B in Figure 2 plot the mean cost in the preview conditions at set sizes 4 and 8 . Negative values on the ordinate represent a decrease in sensitivity compared to the Standard-half condition. The data reveal reduced sensitivity in the Gap condition at set sizes 4 and 8, and the No-gap condition at set size 8 only. A 2 × 2 repeated-measures ANOVA yielded a main effect of preview condition $\left(F_{1,53}=87.23, p<.001, \eta_{\mathrm{p}}^{2}=.62\right)$, no main effect of set size $\left(F_{1,53}=.594\right.$, $\left.p>.05, \eta_{\mathrm{p}}{ }^{2}=.11\right)$, and a significant Preview Condition by Set size interaction $\left(F_{1,53}=\right.$ 7.74, $p=.007, \eta_{\mathrm{p}}{ }^{2}=.13$ ). Compared to Standard-half displays, the reduction in sensitivity was greater in the Gap $(M=-.16, S D=.29)$ than the No-gap condition $(M=-.61, S D=.38)$. The difference between preview conditions was also larger at set size $4(M=.61, S D=.59)$ than $8(M=.31, S D=.51)$, driving the interaction. Planned comparisons using 1-sample $t$-tests revealed a significant decrease in sensitivity compared to the Standard-half baseline in the Gap condition at set sizes $4\left(t_{53}=9.04, p<.001\right)$ and $8\left(t_{53}=8.83, p<.001\right)$, and the No-gap condition at set size $8\left(t_{53}=4.18, p<.001\right)$. Sensitivity in the No-gap condition at set size 4 was equivalent to that in the Standard-half baseline $\left(t_{53}=.65, p>.5\right)$, indicating optimal searches when inhibition and attentional capture provided complementary information about the subset of locations at which the target could appear.

Panels $\mathrm{C}$ and D in Figure 2 plot the mean benefit in the preview conditions at set sizes 4 and 8 . Positive values on the ordinate represent an increase in sensitivity compared to the Standard-full condition. The data illustrate increased sensitivity in the No-gap condition at set sizes 4 and 8, and the Gap condition at set size 8 only. A $2 \times 2$ ANOVA yielded a main effect of preview condition $\left(F_{1,53}=\right.$ 82.28, $\left.p<.001, \eta_{\mathrm{p}}{ }^{2}=.61\right)$, no effect of set size $\left(F_{1,53}=.802, p>.05, \eta_{\mathrm{p}}{ }^{2}=.015\right)$, and a significant Preview Condition by Set size interaction $\left(F_{1,53}=6.23, p=.016, \eta_{\mathrm{p}}{ }^{2}=\right.$ .11). Compared to Standard-full displays, the increase in sensitivity was greater in the No-gap $(M=.67, S D=.44)$ than the Gap condition $(M=.25, S D=.37)$. The difference between preview conditions was larger at set size $4(M=.55, S D=.54)$ than $8(M=.29, S D=.49)$, driving the interaction. Planned comparisons (benefit > 0 ) revealed a significant increase in sensitivity in the No-gap condition at set sizes $4\left(t_{53}=8.54, p<.001\right)$ and $8\left(t_{53}=8.27 p<.001\right)$, and the Gap condition at set size $8\left(t_{53}=5.49, p<.001\right)$; indicating a reliable preview benefit in these displays. Sensitivity in the Gap condition at set size 4 was equivalent to that in the Standard- 
full baseline ( $t_{53}=1.94, p>0.05$ ), indicating observers were unable to optimise search by excluding old items when these reappeared with the onset of new items in the display.

\section{Discussion: Experiment 1}

Experiment 1 contrasted observers' sensitivity in the preview conditions with that in Standard-full and -half displays. The largest benefit was observed in the No-gap condition when the locations of old, and the onset of new objects, provided complementary information about the target's likely position. At set size 4, sensitivity in the No-gap condition was equivalent to that in the Standard-half condition, suggesting observers optimised accuracy by excluding irrelevant locations during search. A preview benefit was also observed at set size 8, although the increased cost compared to Standard-half displays indicates a reduction in the efficacy with which new objects were selected. The data also reveal a significant increase in observers' sensitivity in Gap compared to the Standard-full displays, but only at set size 8. In the Gap condition, this increase can only be attributed to memory-based inhibition of old objects, because the simultaneous presentation of old and new objects negates the predictive utility of capture (Watson \& Kunar, 2010; Kunar et al., 2003). At set size 4, however, estimates of sensitivity in the Gap and Standard conditions were statistically equivalent, suggesting memory-based inhibition is ineffective when the number of onsets small.

The data above reveal two important findings: i) the preview benefit is largest when the locations of old and the onsets of new objects provide complementary information about the target's likely location and ii) the preview benefit occurs when the only information available to guide search is the previously extinguished preview. In the Gap condition, this benefit persists despite the synchronous onset of old and new objects, indicating observers are able to use memory of the preview to suppress irrelevant capture during search. Notably, however, the benefit associated with memory-based inhibition is only apparent when the number of onsets in the search display is greater than four. 
The results above are consistent with a model in which search is biased towards new objects via a mixture of inhibition and stimulus-driven capture. These processes may operate on a spatial representation or one that is sensitive to the features as well as the locations in the preview display (e.g., Andrews et al., 2011). In order to distinguish between these possibilities, Experiment 2 contrasted observers' sensitivity when the orientation of old objects changed at the onset of the search display. This manipulation was designed to introduce a spatiotemporal discontinuity in previewed distractors' features (shape) in the absence of a change in global luminance at old locations (Watson \& Humphreys, 2005).

\section{Method: Experiment 2}

\subsubsection{Observers}

20 observers were recruited to the study: Two were male and age ranged from 18 to 47 years $\left(M_{\text {age }}=21.6, S D=1.61\right)$. All reported normal or corrected-tonormal vision and were naïve to the purpose of the study.

\subsubsection{Apparatus and Stimuli}

The apparatus, stimuli and test conditions were identical to those used in Experiment 1.

\subsubsection{Procedure}

The procedure was identical to that used in Experiment 1 except that the orientation of the distractors in the preview displays was rotated \pm 180 degrees of those in the search display. At the onset of the search display, the rotation of old objects changed to match new objects in the search display. Figure 3 illustrates this manipulation in the No-gap and Gap conditions. 


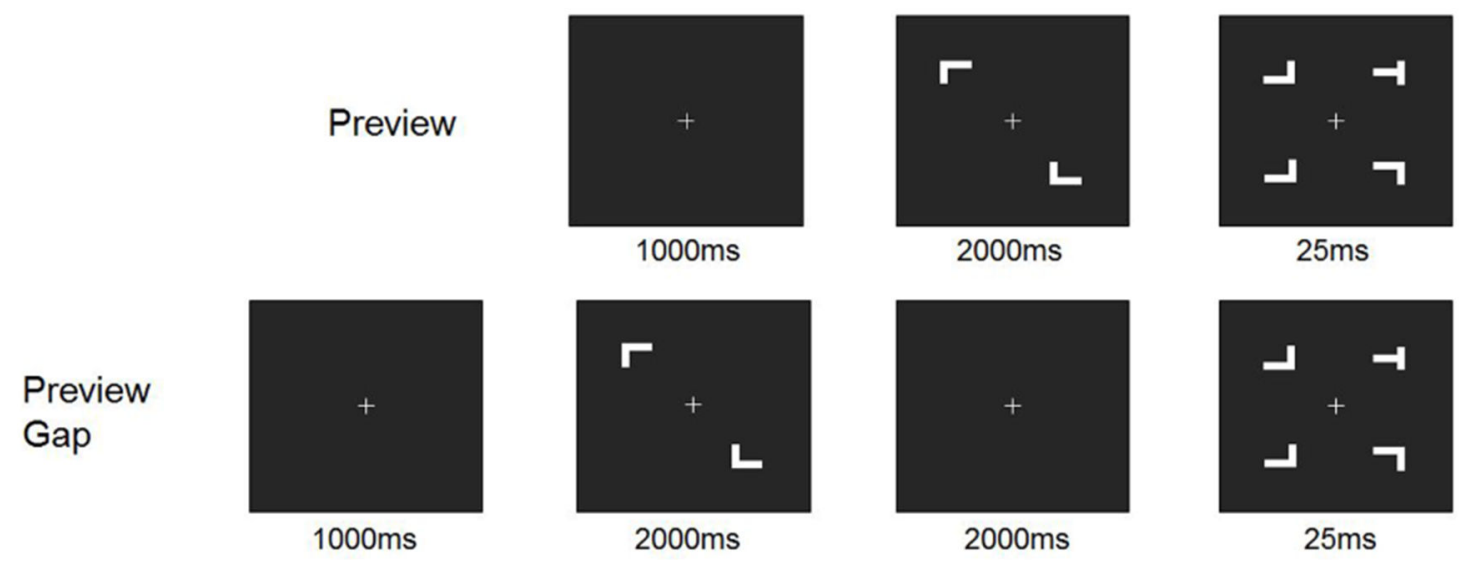

Figure 3. Sequence of events on a target-present trial at set size 4 in the No-gap and Gap conditions in Experiment 2.

\section{Results: Experiment 2}

\subsubsection{Accuracy Data}

Standard-full displays at set size 4 and Standard-half displays at set size 8 were equivalent; thus data for the two conditions were averaged. A 3 x 2 repeated measures ANOVA on proportion correct with search type (Standard-full, No-gap and Gap) and set size $(4,8)$ as within-subjects factors yielded a main effect of set size $\left(F_{2,38}=114, p<0.001, \eta_{p}^{2}=0.858\right)$. Neither the main effect of search type $\left(F_{2,38}\right.$ $=2.688, p>0.05, \eta_{p}^{2}=0.107$ ) or the Search type $\mathrm{x}$ Set size interaction were significant $\left(F_{2,38}=0.286, p>0.05, \eta_{p}^{2}=0.015\right)$. The analyses, therefore, reveal statistically equivalent decreases in accuracy as a function of set size in the Standard-full and preview conditions.

Table 3. Mean proportion of hits $[p(\mathrm{H})]$, false alarms $[p(\mathrm{~F})]$ and correct responses $[p[\mathrm{C})]$ by set size and search condition in Experiment 2. S-half and S-full denote standard-full displays respectively.

\begin{tabular}{lcccccc}
\hline & \multicolumn{3}{c}{ Set Size 4} & \multicolumn{3}{c}{ Set Size 8 } \\
\cline { 2 - 7 } Condition & $p(\mathrm{H})$ & $p(\mathrm{~F})$ & $P(\mathrm{C})$ & $p(\mathrm{H})$ & $p(\mathrm{~F})$ & $p(\mathrm{C})$ \\
\hline S-half & 0.91 & 0.06 & 0.93 & 0.88 & 0.13 & 0.87 \\
No-Gap & 0.88 & 0.14 & 0.87 & 0.73 & 0.17 & 0.78 \\
Gap & 0.88 & 0.11 & 0.89 & 0.73 & 0.12 & 0.81 \\
S-full & 0.88 & 0.12 & 0.88 & 0.72 & 0.17 & 0.77 \\
\hline
\end{tabular}


INHIBITION AND FACILITATION IN PREVIEW SEARCH

\subsubsection{Model estimates and fits}

Table 4 presents the mean parameter estimates of the best fitting model for each observer in standard and preview searches at set sizes 4 and 8 . As in Experiment 1, estimates for each type of search reveal a general decrease in $d^{\prime}$ and an increase in $\lambda$ as set sizes in the standard and preview displays increase.

Table 4. Mean estimated model parameters and fits by set size and search condition in Experiment 2.

\begin{tabular}{llrcrrrc}
\hline & & \multicolumn{3}{c}{ Full Display } & \multicolumn{3}{c}{ Half Display } \\
\cline { 3 - 7 } Search & S Size & $d^{\prime}$ & $\log (\lambda)$ & $\chi^{2}$ & $d^{\prime}$ & $\log (\lambda)$ & $\chi^{2}$ \\
\hline Standard & 4 & 3.31 & -0.60 & 0.64 & 3.62 & -0.43 & 0.54 \\
& 8 & 2.63 & 0.22 & 0.06 & 3.27 & -0.58 & 0.22 \\
No-gap & 4 & 3.27 & -0.56 & 0.34 & 3.02 & -0.47 & 0.23 \\
& 8 & 2.67 & 0.11 & 0.13 & 2.41 & 0.15 & 0.13 \\
Gap & 4 & 3.37 & -0.29 & 0.44 & 3.15 & -0.27 & 0.18 \\
& 8 & 2.92 & 0.43 & 0.28 & 2.69 & 0.49 & 0.07 \\
\hline
\end{tabular}

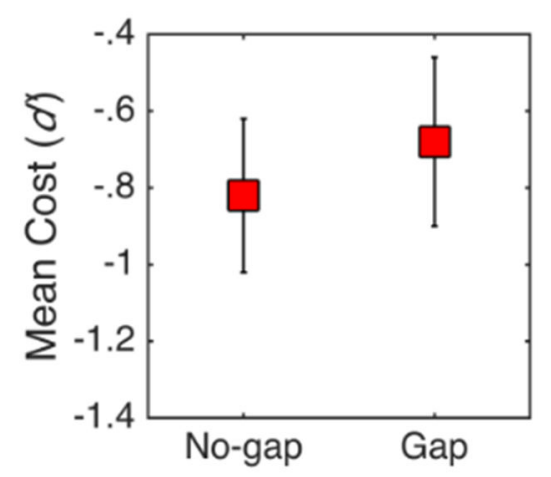

Set Size 4

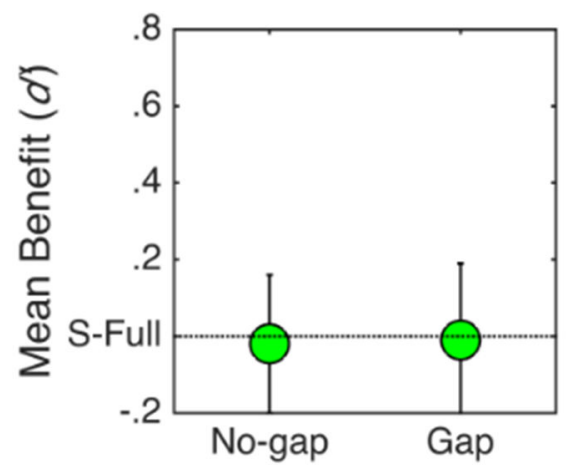

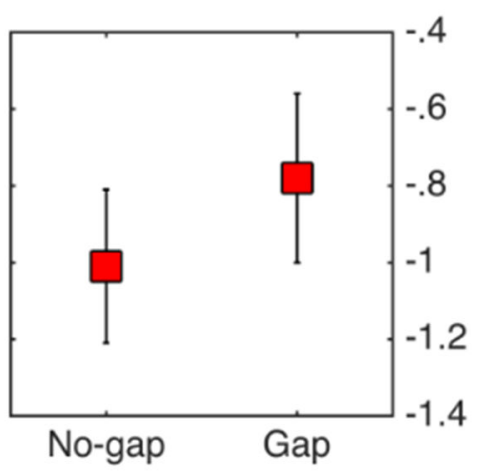

Set Size 8

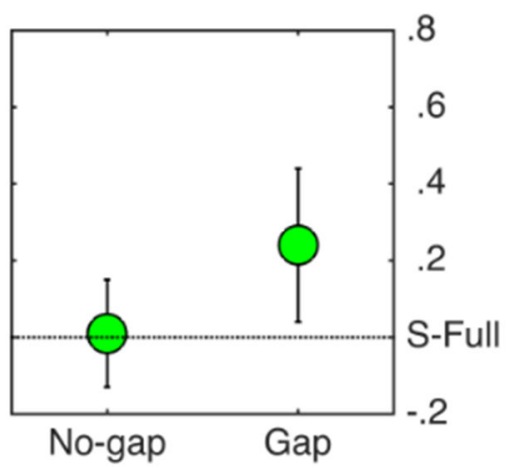

Figure 4. Mean cost and benefit estimates against Standard-half (panels A and B) and Standard-full (panels C and D) baselines in the No-gap and Gap conditions at set sizes 4 and 8. Error bars denote standard errors of the means. 
Panels A and B in Figure 4 plot the mean cost in the preview conditions at set sizes 4 and 8 . Negative values on the ordinate represent a decrease in sensitivity in preview compared to Standard-half displays. The data reveal reduced sensitivity in the No-gap conditions at set sizes $4(M=-82, S D=.80)$ and $8(M=-1.13, S D=.70)$. Sensitivity was also reduced in the Gap conditions at set sizes $4(M=-.68, S D=.66)$ and $8(M=-.90, S D=.88)$. In contrast to Experiment 1 , the reduction in sensitivity was smaller in the Gap than the No-gap condition. A 2 x 2 repeated-measures ANOVA yielded non-significant effects of preview condition $\left(F_{1,19}=2.515, p>.05, \eta_{\mathrm{p}}{ }^{2}=.117\right)$ and set size $\left(F_{1,19}=1.226, p>.05, \eta_{\mathrm{p}}{ }^{2}=\right.$ $.061)$, and a non- significant Preview Condition by Set size interaction $\left(F_{1,53}=.235\right.$, $p>.05, \eta_{\mathrm{p}}{ }^{2}=.12$ ). Planned comparisons for the preview against Standard-half conditions (cost $>0$ ) revealed reliable reductions in sensitivity in the No-gap condition at set sizes $4\left(t_{19}=4.60, p<.001\right)$ and $8\left(t_{19}=7.16, p<.001\right)$ and the Gap condition at set sizes $4\left(t_{19}=4.63, p<.001\right)$ and $8\left(t_{19}=4.61, p<.001\right)$.

Panels $\mathrm{C}$ and $\mathrm{D}$ in Figure 4 plot the mean benefit in the preview conditions at set sizes 4 and 8 . Positive values on the ordinate represent an increase in sensitivity compared to the Standard-full condition. At set size 4 , changing the orientation of old objects completely abolished the preview benefit in the No-gap $(M=-.02, S D=.77)$ and Gap conditions $(M=-.01, S D=.56)$. At set size 8 , the preview benefit was also abolished in the No-gap condition $(M=-.01, S D=.58)$, while a small benefit was observed in the Gap condition $(M=.24, S D=.45)$. A $2 \times 2$ ANOVA yielded non-significant main effects of preview condition $\left(F_{1,19}=1.102, p\right.$ $\left.>.05, \eta_{\mathrm{p}}^{2}=.055\right)$ and set size $\left(F_{1,19}=.776, p>.05, \eta_{\mathrm{p}}{ }^{2}=.039\right)$, and a non-significant Preview Condition by Set size interaction $\left(F_{1,19}=1.579, p>.05, \eta_{\mathrm{p}}{ }^{2}=.077\right)$. Planned comparisons using 1-tailed $t$-tests (benefit $>0$ ) revealed a significant preview benefit in the Gap condition at set size 8 only $\left(t_{19}=2.433, p=.0125\right)$. Sensitivities in the Gap condition at set size $4\left(t_{19}=.108, p>.05\right)$ and the No-gap condition at set size $4\left(t_{19}=.125, p>.05\right)$ and $8\left(t_{19}=.108, p>.05\right)$ were statistically equivalent to those in Standard-full displays.

The analyses above indicate large costs and no significant benefit in the Nogap condition when the orientation of previewed items changed. In the Gap condition, there was no benefit at set size 4 but at set size 8 , a small reliable benefit 
INHIBITION AND FACILITATION IN PREVIEW SEARCH

was obtained. This replicates the pattern of data in the Gap condition in Experiment 1.

\section{Discussion: Experiment 2}

Experiment 2 contrasted observers' sensitivity in the standard and preview search when previewed distractors rotated at the onset of the search display. This manipulation completely abolished the preview benefit in the No-gap condition at set sizes 4 and 8. In the Gap condition, planned comparisons revealed a significant preview benefit at set size 8 only. Comparing the cost and benefit estimates in Figures 2 and 4 also reveals a distinction in the effect of preview conditions in Experiments 1 and 2. In No-gap displays, changing the orientation of the distractors increased the cost and abolished the preview benefit at set sizes 4 and 8. In the Gap condition, however, estimated costs and benefits were comparable across the two experiments. The results, therefore, reveal a small but reliable preview benefit at set size 8 in the Gap condition when the orientation of the distractors remains constant and changes.

\section{General Discussion}

The current study investigated whether the preview benefit is abolished when: i) old and new items appear at the same time and ii) the onset of new objects are accompanied by a spatiotemporal discontinuity in the shape of old objects. To do this, we compared observers' responses when inhibition at old locations, and attentional capture at new locations, provided complementary and conflicting information about the likely position of the target. The results show the preview benefit is largest when inhibition and attentional capture provide complementary spatial information. In Experiment 1, sensitivity in the No-gap condition was comparable to that in the Standard-half display at set size 4, indicating observers optimised performance by excluding objects at old locations during search. This benefit was completely abolished in Experiment 2, when the rotation of previewed distractors produced a discontinuity in the spatial arrangement of their features. Significant preview benefits were also observed in the Gap conditions in 
Experiments 1 and 2 at set size 8, where the simultaneous onset of old and new objects negated the predictive utility of attentional capture. In this situation, observers must rely on information about the previous location of old items to prioritise relevant locations in the face of conflicting capture. This resistance to irrelevant change is a core feature of VWM, and indicates the preview benefit is not necessarily reset by onsets or orientation change at inhibited locations (AlAidroos et al., 2012; Phillips, 1974; Jiang \& Wang, 2004). Moreover, the increase in sensitivity in the Gap compared to the Standard-full conditions shows observers (partially) suppressed attentional capture at old locations when it was nonpredictive of the target's location. This indicates a level of top-down control over stimulus-driven capture at previously attended locations during search, and highlights the role of VWM in biasing selection towards unattended locations (AlAidroos, et al., 2012; Emrich, Ruppel Al-Aidroos, Pratt \& Ferber, 2008; Folk, Remington, \& Wright, 1994; Kiss, Jolicœur, Dell'Acqua, \& Eimer, 2008; Olivers, Humphreys, \& Braithwaite, 2006; Osugi \& Murakami, 2015).

The preservation of the preview benefit in the Gap condition is consistent with inhibition via a robust representation of old items in the display. This finding presents a challenge to explanations based purely on stimulus-capture at new locations (Donk \& Theeuwes, 2001) or the segregation of old and new items via temporal asynchrony (Jian, Chun \& Marks, 2002). In our study, the synchronous onset of old and new objects did not abolish the preview benefit in the Gap condition, indicating observers used the remembered locations of old objects to guide search. The asymmetric pattern of benefits across set size in the Gap condition, however, was unexpected. In the Gap condition, the preview benefit was specific to set size 8 . This suggests the relative contribution of inhibition to search is inversely related to the number of locations at which capture occurs. Jiang and Wang (2004) interpreted a similar dependency as evidence that preview search is guided by the spatial representation of new objects in VWM plus an unlimited, fast-decaying memory of temporal asynchrony. In the current experiment, search displays were extremely brief (24-ms); indicating inhibition influences the accumulation of evidence for the target within a single fixation. This limits the time available to transfer the spatial coordinates of new objects into 
VWM, and suggests inhibition biases selection at, or shortly after, the onset of the search display.

Previous research investigating RT benefits associated with the onset of new objects during search has also revealed an inverse relationship between the number of onsets in the display and the speed of target identification (Yantis \& Johnson, 1990; Yantis \& Jones, 1991). In these studies, a model in which capture prioritised a set of up to four objects best described RT-benefits. In a more recent study, Sunny \& von Mühlenen (2013) found capture yielded the largest decrease in RTs when the target appeared at a single, or one of two, new locations. Estimated capacity-limits for inhibition during search are generally higher; ranging from around five to 20 objects (e.g., Jiang et al., 2002; Osugi et al., 2015; Watson \& Kunar, 2012). Assuming inhibition and capture represent separate resources, this asymmetry would have driven differences in the magnitude of the preview benefit at set sizes four and eight in the Gap condition, because the proportionate decrease in capture at the larger set size would have had less impact on inhibition at old locations. As the distribution of non-predictive onsets increases with set size, the contribution of memory-based inhibition during search becomes more obvious; reducing the cost and increasing the benefit observed in Gap compared to Standard-full displays.

The interpretation of the data above is consistent with a SDT/BO model that assigns negative and positive weights at old and new locations respectively (Allen \& Humphreys, 2007; Osugi \& Murakami, 2015; Shimozaki et al., 2012). Experiment 2 investigated whether these processes are sensitive to changes in the spatiotemporal coherence of old objects. Previous experiments have shown the preview benefit is abolished when the shape of old objects changes at the onset of search (Watson and Humphreys, 1997; 2002). This reduction, which occurs in the absence of global luminance changes, indicates inhibition is reset when sensory change at old locations signals the appearance of a new object. Consistent with these findings, rotating the distractors completely abolished the preview benefit in the No-gap condition. This suggests spatiotemporal discontinuity elicited a reevaluation of previewed objects when the search display appeared. In this case, the disruption of the preview benefit in the No-gap condition is consistent with inhibition that is sensitive to the features as well as the locations of previewed 
objects (Braithwaite \& Humphreys, 2007; Watson et al., 2003).

In contrast to the above, the maintenance of the preview benefit in the Gap condition is difficult to reconcile with feature-based inhibition. In Gap displays, the previewed objects were rotated $\pm 180^{\circ}$ before reappearing with the search display. Spatiotemporal discontinuity at old locations, therefore, did not reset inhibition in the presence of the gap. The difference between the No-gap and Gap conditions may reflect feature- and space-based inhibition in the presence and absence of the gap respectively. A more parsimonious explanation, however, is the difference reflects the salience of the sensory transients in each condition. In Experiment 2, rotating the distractors produced apparent motion at old locations as well as local luminance changes. Motion-onsets have been shown to capture attention during search (Al-Aidroos, et al., 2010) and would have been most salient in the No-gap condition when change occurred on adjacent frames (Petersik, 1989). Memory-based inhibition of irrelevant capture is likely to depend on the salience of the eliciting stimulus (Abrams \& Christ, 2003; Folk et al., 1994) and motion-onsets may have elicited a larger orienting response at old locations in the No-gap condition. In this situation, persistent inhibition in the Gap condition would reflect a decrease in the positive weight assigned to old locations when inhibition and capture combine.

The inhibition observed in our Gap condition contrasts with previous results indicating inhibition is reset when previewed distractors reappear or change shape (Watson \& Humphreys, 1997; 2002; Kunar et al., 2003). This discrepancy may reflect our use of a SDT/BO analysis to isolate changes in sensitivity from changes in response bias during search. Very few studies have investigated changes in the accuracy of standard and preview searches, and RTs are influenced by perceptual as well as post-perceptual factors. Our analyses revealed a greater tendency to report the target absent as set size increased in both experiments. In the preview conditions, this shift towards more conservative response criteria as spatial uncertainty increases, predicts a slowing of responses, as observers require more information to accept or reject the presence of the target (Palmer, Verghese, \& Pavel, 2000; Palmer, 1998). In this case, the increase in RTs when old and new items appear together in previous studies may reflect a slowing of the decision process rather than sensitivity during search. 
Another difference between our own and previous research is the set sizes we employed. Although the majority of preview studies have included set sizes four and eight, most have also included set sizes up to 16 (e.g., Kunar et al., 2003; Watson \& Humphreys, 1997; Watson \& Kunar, 2010). Recent work by Al-Aidroos and colleagues (2012) indicates inhibition during search is most effective when the number of old items falls within the capacity of VWM. Studies investigating eye movements during search have also shown the likelihood of refixations increases once the observer has searched between four and twelve locations (Emrich, Ruppel, Al-Aidroos \& Pratt, 2008; McCarley, Wang, Kramer, Irwin \& Peterson, 2003; Peterson, Kramer, Wang, Irwin \& McCarley, 2001). In overt search, this finding has been attributed to memory-based inhibition of previously attended locations. In the current study, inhibition in the Gap conditions may have been informed by a similar mechanism, because the number of old objects never exceeded four. Distinguishing inhibitory mechanisms during covert and overt search is difficult, because capacity estimates are likely to be affected by changes in the retinal location of objects as well as the acquisition of information over time. Extending the current design to include larger set sizes, however, may distinguish the robust inhibition observed in this study from the more fragile inhibition thought to operate in larger displays (Al-Aidroos et al., 2012; Jiang \& Wang, 2004).

The Gap condition in the current study was designed to isolate memorybased inhibition from stimulus-driven capture during search. Using the same procedure, Kunar and colleagues (2003) showed the RT benefit associated with a briefly presented preview was increased by an earlier exposure of the same objects. In our study, the use of the SDT/BO model provides direct evidence that observers can use the locations of the previously extinguished preview to increase sensitivity during search. While these findings show this procedure can be effective, conflict between inhibition and irrelevant capture at old locations is likely to underestimate the contribution of the former during search. An alternative way to isolate memory-based inhibition in preview search is to mask the sensory events that capture attention (Irwin \& Humphreys, 2013; Watson \& Kunar, 2010; von Mühlenen, Watson, \& Gunnell, 2013). In common with our own results, studies adopting this approach have revealed a partial preview benefit when luminance onsets associated with new objects are occluded or masked. 
Extending these paradigms to include a Gap condition would allow inhibition at old locations to be quantified in the presence and absence of irrelevant capture. Parametrically modulating the luminance of the onsets during search may also provide further insight into the way salience affects inhibition during search when memory and capture provide complementary and conflicting sources of information.

In conclusion, the findings of the current study are consistent with a model in which memory-based inhibition and stimulus-driven facilitation combine to guide the selection of relevant objects during search (Bundesen, 1990; Desimone \& Duncan, 1995; Hyun, Woodman, Vogel, Hollingworth, \& Luck, 2009; Woodman, Luck, \& Schall, 2007). When inhibition and attentional capture provide complementary sources of information, both mechanisms combine to increase sensitivity. When inhibition and attentional capture provide conflicting sources of information, their combination at old locations appears to reduce the efficacy of selection. Comparisons of $d^{\prime}$ in the preview and standard search conditions suggest this reflects increased spatial uncertainty about the subset of locations that can be excluded from search (Allen \& Humphreys, 2007; Gould, Wolfgang, \& Smith, 2007; Shimozaki et al., 2012; Swensson \& Judy, 1981). In the Gap condition, the maintenance of inhibition in the face of irrelevant capture supports the assertion that that VWM can bias selection towards previously unattended locations during search (Al-Aidroos et al., 2012; Emrich et al., 2008; McCarley et al., 2003). In addition, our data indicate the contribution of memory-based inhibition to the preview benefit is sensitive to both the number and salience of objects that elicit capture during search (Jiang \& Wang, 2004; Watson \& Humphreys, 1997; Yantis \& Johnson, 1990; Yantis \& Jones, 1991). This dependency suggests efficient search relies on the effective integration of separate forms of guidance rather than a single unitary resource. Investigating whether this relationship generalises to larger displays, is likely to provide important information about the way these processes interact when the number of new and old items exceeds the capacity of VWM during search.

\section{Acknowledgments}


We would like to thank Derrick Watson and two anonymous reviewers for their constructive comments on an earlier version of the manuscript.

\section{References}

Abrams, R. A., \& Christ, S. E. (2003). Motion onset captures attention. Psychological Science, 14(5), 427-432.

Al-Aidroos, N., Emrich, S. M., Ferber, S., \& Pratt, J. (2012). Visual working memory supports the inhibition of previously processed information: Evidence from preview search. Journal of Experimental Psychology: Human Perception and Performance, 38(3), 643-663. doi:10.1037/a0025707

Al-Aidroos, N., Guo, R. M., \& Pratt, J. (2010). You can't stop new motion: Attentional capture despite a control set for colour. Visual Cognition, 18(6), 859-880.

Allen, H. a., \& Humphreys, G. W. (2007). A psychophysical investigation into the preview benefit in visual search. Vision Research, 47, 735-745. doi:10.1016/j.visres.2006.11.007

Andrews, L. S., Watson, D. G., Humphreys, G. W., \& Braithwaite, J. J. (2011). Flexible feature-based inhibition in visual search mediates magnified impairments of selection: Evidence from carry-over effects under dynamic preview-search conditions. Journal of experimental psychology: human perception and performance, 37(4), 1007.

Barrett, D. J. K., \& Zobay, O. (2014). Attentional control via parallel targettemplates in dual-target search. PLoS ONE, 9(1). doi:10.1371/journal.pone.0086848

Belopolsky, A. V, Schreij, D., \& Theeuwes, J. (2010). What is top-down about contingent capture? Attention, Perception \& Psychophysics, 72, 326-341. doi:10.3758/APP.72.2.326

Brainard, D. H. (1997). The Psychophysics Toolbox. Spatial Vision, 10, 433-436. doi:10.1163/156856897X00357

Braithwaite, J. J., Hulleman, J., Watson, D. G., \& Humphreys, G. W. (2006). Is it impossible to inhibit isoluminant items, or does it simply take longer? Evidence from preview search. Perception \& Psychophysics, 68, 290-300. doi:10.3758/BF03193676 
Braithwaite, J. J., \& Humphreys, G. W. (2007). Filtering items of mass distraction: Top-down biases against distractors are necessary for the feature-based carry-over to occur. Vision Research, 47, 1570-1583.

doi:10.1016/j.visres.2007.02.019

Bundesen, C. (1990). A theory of visual attention. Psychological Review, 97, 523547. doi:10.1037/0033-295X.97.4.523

Cameron, E. L., Eckstein, M., Tai, J., \& Carrasco, M. (2004). Signal detection theory applied to three visual search tasks - identification, yes/no detection and localization. Spatial Vision, 17(4), 295-325.

doi:10.1163/1568568041920212

Cowan, N. (2001). The magical number 4 in short-term memory: a reconsideration of mental storage capacity. The Behavioral and Brain Sciences, 24, 87-114; discussion 114-185. doi:10.1017/S0140525X01003922

Desimone, R., \& Duncan, J. (1995). Neural mechanisms of selective visual attention. Annual Review of Neuroscience, 18, 193-222. doi:10.1146/annurev.ne.18.030195.001205

Di Lollo, V., Enns, J. T., \& Rensink, R. A. (2000). Competition for consciousness among visual events: the psychophysics of reentrant visual processes. Journal of Experimental Psychology. General, 129, 481-507. doi:10.1037/0096-3445.129.4.481

DM Green, J. S., Green, D. M., \& Swets, J. A. (1966). Signal detection theory and psychophysics. Society, 1, 521. doi:10.1901/jeab.1969.12-475

Donk, M., Agter, F., \& Pratt, J. (2009). Effects of luminance change in preview search: Offsets and onsets can be concurrently prioritized but not in isolation. Acta Psychologica, 130, 260-267. doi:10.1016/j.actpsy.2009.01.006

Donk, M., \& Theeuwes, J. (2001). Visual marking beside the mark: prioritizing selection by abrupt onsets. Perception \& Psychophysics, 63, 891-900. doi:10.3758/BF03194445

Donk, M., \& Theeuwes, J. (2003). Prioritizing selection of new elements: bottomup versus top-down control. Perception \& Psychophysics, 65, 1231-1242. doi:10.3758/BF03194848

Eckstein, M. P. (2011). Visual search: A retrospective. Journal of Vision, 11, 14-14. doi:10.1167/11.5.14

Emrich, S. M., Ruppel, J. D. N., Al-Aidroos, N., Pratt, J., \& Ferber, S. (2008). Out with the old: inhibition of old items in a preview search is limited. Perception \& Psychophysics, 70, 1552-1557. doi:10.3758/PP.70.8.1552 
Emrich, S. M., Al-Aidroos, N., Pratt, J., \& Ferber, S. (2010). Finding memory in search: The effect of visual working memory load on visual search. The Quarterly Journal of Experimental Psychology, 63(8), 1457-1466.

Folk, C. L., Remington, R. W., \& Wright, J. H. (1994). The structure of attentional control: contingent attentional capture by apparent motion, abrupt onset, and color. Journal of Experimental Psychology. Human Perception and Performance, 20, 317-329. doi:10.1037/0096-1523.20.2.317

Green, D., \& Swets, J. (1974). Signal detection theory and psychophysics. Melbourne FL: Robert E. Kreiger Publishing Co., Inc.

Gould, I. C., Wolfgang, B. J., \& Smith, P. L. (2007). Spatial uncertainty explains exogenous and endogenous attentional cuing effects in visual signal detection. Journal of Vision, 7, 4.1-17. doi:10.1167/7.13.4

Hollingworth, A., Richard, A. M., \& Luck, S. J. (2008). Understanding the function of visual short-term memory: transsaccadic memory, object correspondence, and gaze correction. Journal of Experimental Psychology. General, 137, 163181. doi:10.1037/0096-3445.137.1.163

Humphreys, G. W., Olivers, C. N. L., \& Braithwaite, J. J. (2006). The time course of preview search with color-defined, not luminance-defined, stimuli. Perception \& Psychophysics, 68, 1351-1358. doi:10.3758/BF03193733

Humphreys, G. W., Stalmann, B. J., \& Olivers, C. (2004). An analysis of the time course of attention in preview search. Perception \& Psychophysics, 66(5), 713-730. doi:10.3758/BF03194967

Hyun, J., Woodman, G. F., Vogel, E. K., Hollingworth, A., \& Luck, S. J. (2009). The comparison of visual working memory representations with perceptual inputs. Journal of Experimental Psychology. Human Perception and Performance, 35(4), 1140-1160. doi:10.1037/a0015019

Irwin, D. E., \& Humphreys, G. W. (2013). Visual marking across eye blinks. Psychonomic bulletin \& review, 20(1), 128-134.

Jacobsen, T., Humphreys, G. W., Schröger, E., \& Roeber, U. (2002). Visual marking for search: Behavioral and event-related potential analyses. Cognitive Brain Research, 14, 410-421. doi:10.1016/S0926-6410(02)00143-X

Jiang, Y., Chun, M. M., \& Marks, L. E. (2002). Visual marking: selective attention to asynchronous temporal groups. Journal of Experimental Psychology. Human Perception and Performance, 28(3), 717-730. doi:10.1037/00961523.28.3.717

Jiang, Y., \& Wang, S. W. (2004). What kind of memory supports visual marking? Journal of Experimental Psychology. Human Perception and Performance, 30(1), 79-91. doi:10.1037/0096-1523.30.1.79 
Kiss, M., \& Eimer, M. (2011). Faster target selection in preview visual search depends on luminance onsets: behavioral and electrophysiological evidence. Attention, Perception \& Psychophysics, 73, 1637-1642. doi:10.3758/s13414011-0165-z

Kiss, M., Jolicœur, P., Dell'Acqua, R., \& Eimer, M. (2008). Attentional capture by visual singletons is mediated by top-down task set: New evidence from the N2pc component. Psychophysiology, 45(6), 1013-1024. doi:10.1111/j.14698986.2008.00700.x

Kleiner, M., Brainard, D., Pelli, D., Ingling, A., Murray, R., \& Broussard, C. (2007). What's new in Psychtoolbox-3? Perception 36 ECVP Abstract Supplement, 14. doi:10.1068/v070821

Kunar, M. A., Humphreys, G. W., \& Smith, K. J. (2003). History Matters The Preview Benefit in Search Is Not Onset Capture. Psychological Science, 14(2), 181-185.

Kunar, M. A., Humphreys, G. W., Smith, K. J., \& Hulleman, J. (2003). What is "marked" in visual marking? Evidence for effects of configuration in preview search. Perception \& Psychophysics, 65, 982-996. doi:10.3758/BF03194828

Kupinski, M. A., Hoppin, J. W., Clarkson, E., \& Barrett, H. H. (2003). Ideal-observer computation in medical imaging with use of Markov-chain Monte Carlo techniques. Journal of the Optical Society of America. A, Optics, Image Science, and Vision, 20, 430-438. doi:10.1364/JOSAA.20.000430

Luck, S. J., \& Vogel, E. K. (1997). The capacity of visual working memory for features and conjunctions. Nature, 390(1996), 279-281. doi:10.1038/36846

Mazyar, H., van den Berg, R., \& Ma, W. J. (2012). Does precision decrease with set size? Journal of Vision, 12, 10-10. doi:10.1167/12.6.10

McCarley, J. S., Wang, R. F., Kramer, A. F., Irwin, D. E., \& Peterson, M. S. (2003). How much memory does oculomotor search have? Psychological Science, 14(5), 422-426.

McElree, B., \& Carrasco, M. (1999). The temporal dynamics of visual search: evidence for parallel processing in feature and conjunction searches. Journal of Experimental Psychology. Human Perception and Performance, 25, 15171539.

Olivers, C. N. L., Humphreys, G. W., \& Braithwaite, J. J. (2006). The preview search task: Evidence for visual marking. Visual Cognition, 14, 716-735. doi:10.1080/13506280500194188

Osugi, T., \& Murakami, I. (2015). Onset of background dynamic noise attenuates preview benefit in inefficient visual search. Vision research, 112, 33-44. 
Palmer, J. (1994). Set-size effects in visual search: the effect of attention is independent of the stimulus for simple tasks. Vision Research, 34, 17031721. doi:10.1016/0042-6989(94)90128-7

Palmer, J. (1998). Attentional effects in visual search: Relating search accuracy and search time. In R. Ward (Ed.) Visual Attention. (pp. 348-388). Oxford: Oxford University Press.

Palmer, J., Verghese, P., \& Pavel, M. (2000). The psychophysics of visual search. Vision Research, 40, 1227-1268. doi:10.1016/S0042-6989(99)00244-8

Phillips, W. A. (1974). On the distinction between sensory storage and shortterm visual memory. Perception \& Psychophysics. doi:10.3758/BF03203943

Petersik, J. T. (1989). The two-process distinction in apparent motion. Psychological Bulletin, 106(1), 107.

Peterson, M. S., Kramer, A. F., Wang, R. F., Irwin, D. E., \& McCarley, J. S. (2001). Visual search has memory. Psychological Science, 12(4), 287-292.

Pylyshyn, Z. W., \& Storm, R. W. (1988). Tracking multiple independent targets: evidence for a parallel tracking mechanism. Spatial Vision, 3, 179-197. doi:10.1163/156856888X00122

Shimozaki, S. S. (2010). Uncued and cued dynamics measured by response classification. Journal of Vision, 10, 10. doi:10.1167/10.8.10

Shimozaki, S. S., Eckstein, M. P., \& Abbey, C. K. (2003). Comparison of two weighted integration models for the cueing task: linear and likelihood. Journal of Vision, 3, 209-229. doi:10.1167/3.3.3

Shimozaki, S., Schoonveld, W., \& Eckstein, M. (2012). A unified bayesian observer analysis for set size and cueing effects on perceptual decisions and saccades., 12, 1-26. doi:10.1167/12.6.27

Smith, P. L. (2010). Spatial attention and the detection of weak visual signals. In Coltheart V (Ed.) Tutorials in visual cognition, London UK: Psychology Press Ltd. 211-259.

Sunny, M. M., \& von Mühlenen, A. (2013). Attention capture by abrupt onsets: Revisiting the priority tag model. Frontiers in Psychology, 4(December), 1-12. doi:10.3389/fpsyg.2013.00958

Swensson, R. G., \& Judy, P. F. (1981). Detection of noisy visual targets: models for the effects of spatial uncertainty and signal-to-noise ratio. Perception \& Psychophysics, 29(6), 521-534. doi:10.3758/BF03207369

Verghese, P. (2001). Visual search and attention: a signal detection theory approach. Neuron, 31, 523-535. 
Watson, D. G., \& Humphreys, G. W. (1997). Visual marking: prioritizing selection for new objects by top-down attentional inhibition of old objects. Psychological Review, 104(1), 90-122. doi:10.1037/0033-295X.104.1.90

Watson, D. G., \& Humphreys, G. W. (2002). Visual marking and visual change. Journal of Experimental Psychology: Human Perception and Performance, $28(2), 379$.

Watson, D. G., Humphreys, G. W., \& Olivers, C. N. L. (2003). Visual marking: using time in visual selection. Trends in Cognitive Sciences, 7(4), 180-186. doi:10.1016/S1364-6613(03)00033-0

Watson, D. G., \& Humphreys, G. W. (2005). Visual marking: The effects of irrelevant changes on preview search. Perception \& psychophysics, 67(3), 418-434.

Watson, D. G., \& Kunar, M. A. (2010). Visual marking and change blindness: Moving occluders and transient masks neutralize shape changes to ignored objects. Journal of experimental psychology: human perception and performance, 36(6), 1391.

Watson, D. G., \& Kunar, M. A. (2012). Determining the capacity of time-based selection. Journal of experimental psychology: human perception and performance, 38(2), 350.

Wickens, T. D. (2001). Elementary signal detection theory. New York (Vol. 1, p. 262). doi:10.1093/acprof:oso/9780195092509.001.0001

Woodman, G. F., Luck, S. J., \& Schall, J. D. (2007). The role of working memory representations in the control of attention. Cerebral Cortex, 17. doi:10.1093/cercor/bhm065

Yantis, S., \& Johnson, D. N. (1990). Mechanisms of attentional priority. Journal of Experimental Psychology. Human Perception and Performance, 16(4), 812825. doi:10.1037/0096-1523.16.4.812

Yantis, S., \& Jones, E. (1991). Mechanisms of attentional selection: temporally modulated priority tags. Perception \& Psychophysics, 50, 166-178. doi:10.3758/BF03212217

von Mühlenen, A., Watson, D., \& Gunnell, D. O. (2013). Blink and you won't miss it: The preview benefit in visual marking survives internally generated eyeblinks. Journal of Experimental Psychology: Human Perception and Performance, 39(5), 1279. 


\section{Appendix: Derivation of Bayesian Observer Model}

\section{Task description:}

The current study considers a detection task in which the observer has to report the presence or absence of a target in a search display of size $M(M=4$ or 8). Target-present and -absent trials occur with equal probability. As discussed in the main text, there are four variants of the task (standard-full, standard-half, gap and no-gap search displays). In the following, the focus is on the derivation of the Bayesian observer (BO) model for the full display; the application of the formalism to the other tasks is straightforward and will be briefly discussed at the end.

In the standard task, displays on target-absent trials contain 2 kinds of $L$-shaped distractors (designated + and - ), one with a leftward and one a rightward oriented short bar. On a target-absent trial, the search display comprises $M / 2$ distractors of each kind. On a target-present trial, one of the distractors is replaced by a $T$ shaped target (designated 0 ), i.e., the display contains $M / 2-1$ distractors of one kind and $M / 2$ distractors of the other.

Thus, the features that set the mathematical modelling of this task apart from more basic BO models are (i) the presence of two different types of distractors and (ii) the restrictions on the permissible combinations of distractors that can be presented in the search display.

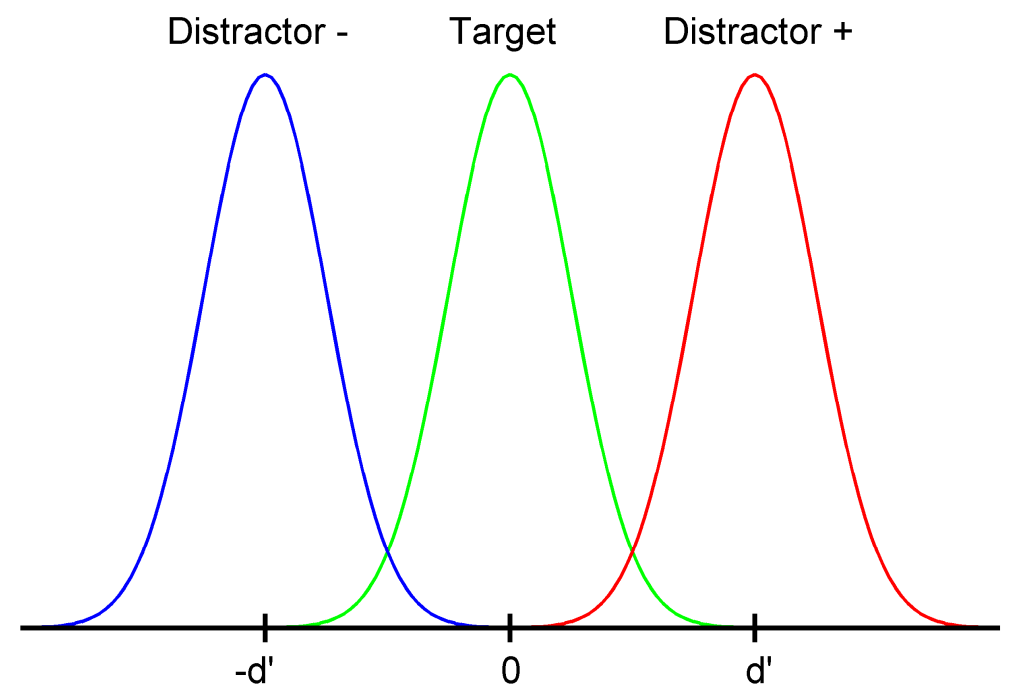

Figure A1. Probability distributions for distractors and target.

Assumptions about the observer:

In accordance with signal-detection theory, we assume that the subject acquires noisy observations of the objects in the search display and records the stimulus values $X_{1}, \ldots, X_{M}$. If location $i$ contains the target, the corresponding stimulus $X_{i}$ is modelled as a random draw from the standard normal distribution with mean 0 and variance 1 . If location $i$ is a distractor, the stimulus is a random draw from a normal distribution with variance 1 and a mean of $d^{\prime}$ or $-d^{\prime}$ for distractor types + 
and -, respectively. These assumptions are based on the positioning of the intersection of the short and long bars, with the intersection for the target ( $T$ shape) falling midway between the intersections of the two distractors ( $L$-shapes).

The Bayesian observer model:

In the BO model, it is assumed that the subject computes the posterior probabilities for target presence and absence given the observed stimuli. The response to the trial then depends on whether the ratio of these probabilities is above a predetermined threshold (criterion).

The mathematical description of the $\mathrm{BO}$ model requires to us introduce some definitions and basic relationships:

1. There are $K_{N}=C(M, M / 2)$ different arrangements of distractors in a target-absent search display of size $M(C(n, m)$ denotes the binomial coefficient indexed by $n$ and $m)$. For example, for $M=4$, there are 6 possible arrangements $\{(++--),(+-+-),(+$ $--+),(-+-+),(-++-),(--++)\}$. For $M=8$, there are 70 arrangements. These $k_{N}$ different arrangements will be denoted $N_{k}, k=1, \ldots, K_{N}$.

2. Substituting a target for any distractor in any of the possible target-absent arrangement produces one of the potential object arrangements in a targetpresent trial. Hence, there are $K_{T}=M^{*} C(M, M / 2)$ different target-present arrangements which will be denoted $T_{k}, k=1, \ldots, K_{T}$.

3. The set of observed stimuli in a given trial is denoted $\mathbf{x}=\left(x_{1}, \ldots, X_{M}\right)$. For a given target-absent (arrangement $N_{k}$, the probability $\mathrm{p}\left(\mathbf{x} \mid N_{k}\right)$ of observing $\mathbf{x}$ is determined by the product

$$
p\left(\mathbf{x} \mid N_{k}\right)=\prod_{i=1}^{M} p\left(x_{i} \mid N_{k, i}\right)
$$

where $N_{k, i}$ is the object (either + or -) at the ith position in the arrangement $N_{k}$ In accordance with our assumptions from SDT, $p(x \mid+)$ and $p(x \mid-)$ are normal distributions with variance 1 and means $d^{\prime}$ and $-d^{\prime}$, respectively. Similarly, for a target-present trial, we have

$$
p\left(\mathbf{x} \mid T_{k}\right)=\prod_{i=1}^{M} p\left(x_{i} \mid T_{k, i}\right)
$$

which now also involves the normal distribution $p(x \mid 0)$ with mean 0 assigned to a target object.

4. The prior probabilities for target presence and absence are given by $p(T)=p(N)=1 / 2$ since target-present and absent trials have the same probability of occurrence. As we do not have additional prior information about the occurrence of object arrangements underlying target-present and -absent trials, their respective prior probabilities are correspondingly set to 
INHIBITION AND FACILITATION IN PREVIEW SEARCH

$$
\begin{aligned}
& p\left(T_{i}\right)=\frac{1}{2 K_{T}}, \\
& p\left(N_{i}\right)=\frac{1}{2 K_{N}} .
\end{aligned}
$$

5. The posterior probabilities for target presence, given the vector of observed stimuli $\mathbf{x}=\left(x_{1}, \ldots, x_{M}\right)$, can be expressed as

$$
p(T \mid \mathbf{x})=\frac{p(\mathbf{x} \mid T) p(T)}{p(\mathbf{x})}=\frac{\sum_{k=1}^{K_{T}} p\left(\mathbf{x} \mid T_{k}\right) p\left(T_{k}\right)}{p(\mathbf{x})} .
$$

The first equality uses Bayes' law whereas in the second the events of target presence or absence were decomposed into the contributions from the underlying object arrangements in the search display. A corresponding relation holds for $p(N \mid \mathbf{x})$.

The Bayesian observer computes the ratio $R(\mathbf{x})$ of the posterior probabilities. With the help of Eq. (5), this can be expressed as

$$
R(\mathbf{x})=\frac{p(T \mid \mathbf{x})}{p(N \mid \mathbf{x})}=\frac{\sum_{k=1}^{K_{T}} p\left(\mathbf{x} \mid T_{k}\right) p\left(T_{k}\right)}{\sum_{k=1}^{K_{N}} p\left(\mathbf{x} \mid N_{k}\right) p\left(N_{k}\right)}
$$

Using Eqs. (1)-(4), $R(\mathbf{x})$ can be computed for any given stimulus set $\mathbf{x}$. The observer chooses a criterion $\lambda$, and a target-present response is supplied whenever $R(\mathbf{x})>$ $\exp (\lambda)$ (or, equivalently, $\log R(\mathbf{x})>\lambda$ ).

As an illustration of Eq. (5), the denominator for $M=4$ is given by

$$
\begin{gathered}
\sum_{k=1}^{K_{N}} p\left(\mathbf{x} \mid N_{k}\right) p\left(N_{k}\right)=p\left(x_{1} \mid+\right) p\left(x_{2} \mid+\right) p\left(x_{3} \mid-\right) p\left(x_{4} \mid-\right) \frac{1}{2 K_{N}} \\
+p\left(x_{1} \mid+\right) p\left(x_{2} \mid-\right) p\left(x_{3} \mid+\right) p\left(x_{4} \mid-\right) \frac{1}{2 K_{N}}+\cdots \\
+p\left(x_{1} \mid-\right) p\left(x_{2} \mid-\right) p\left(x_{3} \mid+\right) p\left(x_{4} \mid+\right) \frac{1}{2 K_{N}} .
\end{gathered}
$$

Computing hit and false-alarm rates:

A key issue in data analysis based on the BO model is the computation of hit and false-alarm rates for given $d^{\prime}$ and $\lambda$. This can be accomplished by means of MonteCarlo simulation. To compute, e.g., the false-alarm rate one can proceed in the following way:

1. At each iteration of the simulation, randomly draw a target-absent arrangement $N_{i}$ from the set of all such arrangements.

2. Simulate a set $\mathbf{x}=\left(x_{1}, \ldots, x_{M}\right)$ of observed stimuli by randomly drawing from the normal distributions $p\left(x_{i} \mid N_{k, i}\right)$ associated with the drawn arrangement $N_{k}$. 
3. Record whether $\mathbf{x}$ would have led the subject to a target-present decision by computing the posterior-probability ratio $R(\mathbf{x})$ according to Eq. (5) and comparing it to the criterion value.

4. Repeat steps 1-3 a large number of times (say, 50,000). The false-alarm rate is then given by the fraction of target-present decision.

The hit rate is computed analogously by drawing from the target-present arrangements. In practical numerical calculations, the computations can be sped up in various ways, for example by re-using the same set of ratios $R(\mathbf{x})$ for varying criteria at fixed $d^{\prime}$ or by using interpolation schemes after computing the rates on an initial grid of $d^{\prime}$ and criterion values.

The dependence of the hit and false-alarm rates on $d^{\prime}$ and set size is illustrated in Fig. A2.

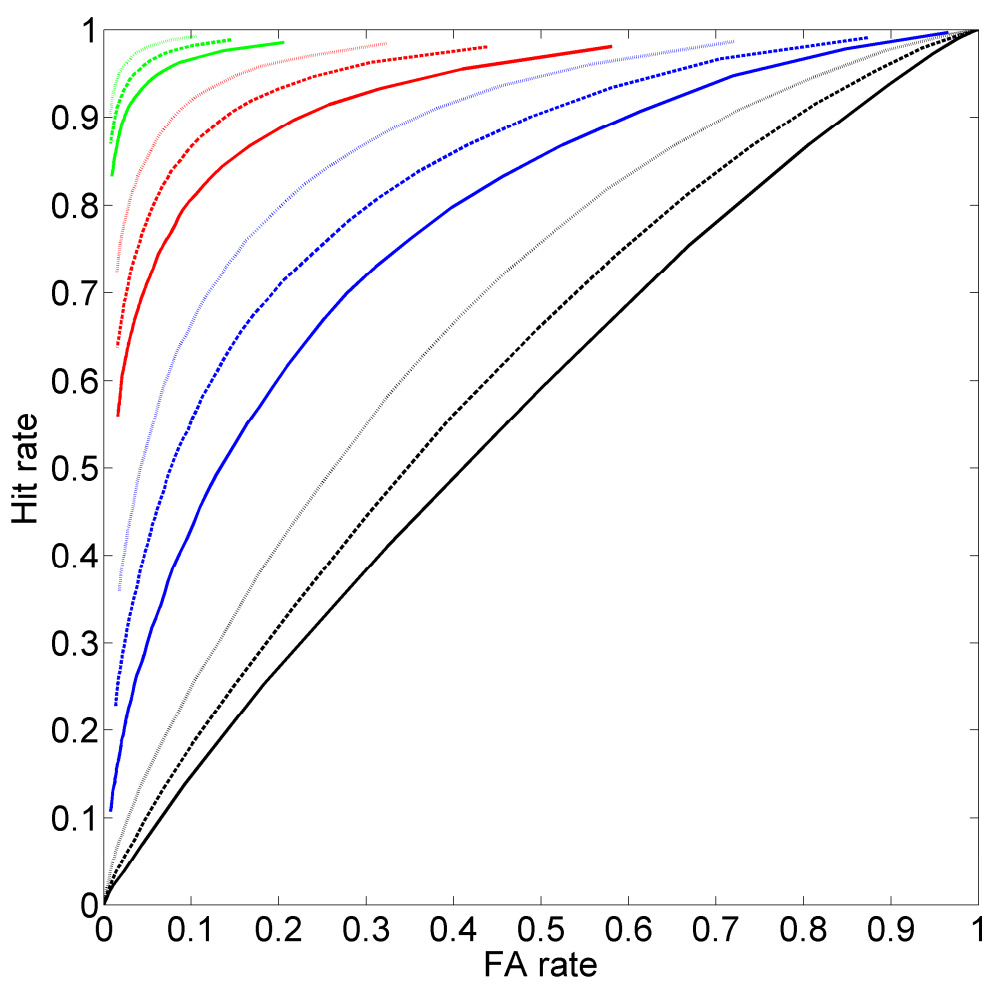

Figure A2. ROC for varying d' and set size. ROC curves are shown for $d^{\prime}=1$ (black), 2 (blue), 3 (red) and 4 (green) and set size 2 (dotted), 4 (dashed) and 8 (solid).

Estimating $d^{\prime}$ and criteria from observed hit and false-alarm rates:

As the above plot suggests, there is a one-to-one correspondence between pairs of hit and false-alarm rates at a given set size and the corresponding BO-model parameters $d^{\prime}$ and $\lambda$. Point estimates of these parameters can therefore be obtained by numerically inverting the map from $d^{\prime}$ and $\lambda$ to the rates. One way to achieve this is by minimizing chi-square, i.e.,

$$
X^{2}\left(d^{\prime}, \lambda\right)=N_{P r e s} \frac{\left[p_{H}\left(d^{\prime}, \lambda\right)-p_{H}^{O b s}\right]^{2}}{p_{H}\left(d^{\prime}, \lambda\right)}+N_{A b s} \frac{\left[p_{F A}\left(d^{\prime}, \lambda\right)-p_{F A}^{O b s}\right]^{2}}{p_{F A}\left(d^{\prime}, \lambda\right)}
$$


as a function of $d^{\prime}$ and $\lambda$. Here, $N_{\text {Pres }}$ and $N_{A b s}$ denote the numbers of targetpresent and -absent trials, respectively, $p_{H}^{O b s}$ and $p_{F A}^{O b s}$ are the observed rates, and $p_{H}\left(d^{\prime}, \lambda\right)$ and $p_{F A}\left(d^{\prime}, \lambda\right)$ describe the rates computed from $d^{\prime}$ and $\lambda$ as explained above. At the estimated values of $d^{\prime}$ and $\lambda$, the computed rates perfectly reproduce the observed ones so that $X^{2}$ equals zero.

Note that the one-to-one correspondence only holds if $p_{H}^{O b s} \geq p_{F A}^{O b s}$ since for all values of $d^{\prime}$ and $\lambda, p_{H}\left(d^{\prime}, \lambda\right) \geq p_{F A}\left(d^{\prime}, \lambda\right)$. In the current study, the case of $p_{H}^{O b s}<$ $p_{F A}^{O b s}$ occurred only very rarely, and under these circumstances, $d^{\prime}$ and $\lambda$ were still estimated by minimizing $X^{2}\left(d^{\prime}, \lambda\right)$.

Analysis of half-display and preview tasks:

The half-display task is treated in the same way as a standard task at half the display size. To determine the preview benefit, the gap and no-gap tasks are analysed like a standard task at the same display size. The $d^{\prime}$ values found in this way are then related to the ones obtained from the standard task.

To compute the preview cost, we make use of the fact that the preview locations are chosen such that they contain an equal number of + and - distractors. The objects at unpreviewed locations thus form valid arrangements for a standard search at half the display size, and the gap and no-gap tasks are therefore analysed as such. 